\title{
The Possible Potentials of Astrotourism in Caucasus
}

\author{
Mohammad Javad Torabi* \\ IAU National Outreach Coordinator (NOC), Iran
}

\begin{abstract}
Astrotourism is not a new topic, but it is certainly a title that has been in the forefront of tourism and astronomy for less than two decades. For nearly half a century, observatories and science centers have been opening their doors to the public on special occasions, such as Astronomy Day. However, for less than a decade, astrotourism has been the constant presence of tourists alongside professional astronomers, especially on weekends. They have made it possible by following all the principles. Until the early 1990s, one of the most important countries in the world to host the world's largest astronomical observatories was the Soviet Union. The Caucasus region in the former Soviet Union hosted very important observatories due to its high altitudes, pure nature, and very low amount of light pollution and, of course, the proper weather in warm seasons. Byurakan in Armenia, Abastumani in Georgia, Shamakhi in Azerbaijan, and BTA-6 in Russia are the four main collections left from that period. Fortunately, nearly two decades after the independence of the countries in the region, the restoration and updating of these observatories have been on the agenda. One of the helping arms to accelerate the revival of these observatories is to take advantage of the potential of astrotourism; especially with the location of these three countries near Iran, which has one of the largest astronomy enthusiast communities in the region.
\end{abstract}

Keywords: Astrotourism, Scientific tourism, Caucasus, Astronomy Outreach, Abastumani, Byurakan, Shamakhi, BTA-6

\section{Introduction}

The night sky has played a key role in the development of civilization, including orientation and navigation, agriculture, calendars, cultural travel, and celebrations Fayos-Solà et al. (2016). In the last two decades, a new role has been created for the night sky: astrotourism with special attention to places with dark skies. However, the naturally dark sky is a rare phenomenon in developed countries. Therefore, it is necessary to protect it. The dark sky is an essential condition for the establishment of Dark Sky Park, which is the basis for increasing area attractiveness from astrotourism viewpoint Labuda et al. (2016). However, astrotourism is not limited to the night. Astrotourism refers to any tourist activity that is provided by the use of the sky day and night. Astronomy-related tourism can be divided into some main types. The first one is connected to cultural and sightseeing tourism. It involves visiting facilities related to astronomy: planetariums, observatories, museums, and others that relate to the development of this field of science. Another type of astrotourism is visiting the areas with a clear, dark sky Mitura et al. (2017). With pristine parks and established infrastructure, astrotourism would be a natural extension of daytime nature tourism into nighttime stargazing Jiwaji (2016).

There are dark-sky awards in the world that accelerate night sky protection against light pollution. Achieving a dark-sky award is undoubtedly an attractive addition to off-season tourism. It is a relatively fast and inexpensive initiative that can attract significant attention to the region MacMillan (2016). Especially in areas with long-standing observatories. Astrotourism includes only travel program visit the observatory, which includes specific astronomical observations, and not just a demonstration of observations by professional astronomers, but direct observation of every individual tourist.

*mjtorabi@gmail.com 
Astrotourists is necessarily, and direct observer, in an astronomical sense Belij \& Tadic (2015); However, this experience is with small telescopes and not professional telescopes.

Regardless of the effort invested in a reasonably complex organization that includes astronomical institutions and instruments, professional astronomers, or so-called science educators, and attractive sites, astrotourism still attracts a small number of people who are lovers of astronomy and mostly, residents of large cities in developed countries Tadic (2016) Since 2009 (International Year of Astronomy, IYA-2009, declared by UNESCO), these activities are developed in Armenia, one the countries in the Caucasus region, that includes observations of starry skies, visits to modern observatories, space museums and planetarium, as well as popular astronomical lectures Mickaelian \& Farmanyan (2016). In order to launch astrotourism, however, more than anything else, it is necessary to provide a platform and facilities and at the same time, enough advertising to implement it. The Caucasus region, known as the Caspian Sea and the Black Sea, with two large Caucasus Mountains and the Lesser Caucasus, is essential for astrotourism in several respects at the confluence of Eastern Europe and West Asia. The less damaged nature of the area, the sky free of light pollution, and, most importantly, the attractive spaces of observatories, given their location in the pristine areas, as well as historical telescopes and domes of these observatories, have given astrotourists a rare opportunity. However, astrotourism has not yet had a long history in the region, providing only a small percentage of an observatory's costs. The reason for this can be found in a series of search factors. What seems to be more important than anything else is the reliance of these observatories on domestic tourists and visitors; this may be due to linguistic differences and difficult access to some of these observatories. However, the author's experience in conducting astrotours with Iranian amateur astronomers showed the high potential of these observatories in astrotourism. This experience was so well-received by Iranian amateur astronomers that each was repeated between two or more times in recent years. In the following, I will review the features, general observing tools, and the type of access to each of these observatories.

\section{Observatories in Caucasus}

\subsection{Abastumani Observatory}

The Abastumani Observatory was founded in 1932 on Mount Khanobili, $240 \mathrm{~km}$ from Tbilisi and $30 \mathrm{~km}$ northwest of Akhaltsikhe, at an altitude of 1,700 meters above sea level. However, early observations on this mountain date back to the 1890s. The ideal observational conditions of this mountain made it possible for Abastumani to host hundreds of astronomers and thousands of eager observers of the sky every year with the establishment of the observatory. One of the main features of this observatory for amateur astronomers and astronomy enthusiasts is the possibility of observation with a $40 \mathrm{~cm}$ refracting telescope with a focal length of $680 \mathrm{~cm}$. The telescope has been active since 1937 and can be called the 50th largest refracting telescope in the world. One of the features of this telescope's observatory is the possibility of changing the mechanical height of the observer's location, which is unique in this region. It is possible to visit this observatory for the first hours after sunset and if the sky is cloudless.

\subsection{Byurakan Observatory}

Byurakan Observatory near Yerevan, Armenia, is the best Caucasus observatory in terms of access to the capital. Launched in 1946, the observatory is located $30 \mathrm{~km}$ from Yerevan, the capital of Armenia. Researchers still use the observatory's 2.6-meter and one-meter telescopes, which has an astonishing history and can be visited daily. The observatory is located at an altitude of 1,400 meters above sea level and is more cloudless than its other Caucasian counterparts. In addition to observing the sky by the 32-cm telescope, astrotourists can visit the large telescopes, the Viktor Ambartsumian House-Museum, along with the opportunity to have a public lecture about astronomy. Byurakan observatory became a popular destination by accurate documentation of its history, easy reservation (by email), and services in three languages, Armenian, English, and Russian. Moreover, the reopening of the observatory's residence for astrotourists has made Byurakan a popular destination 


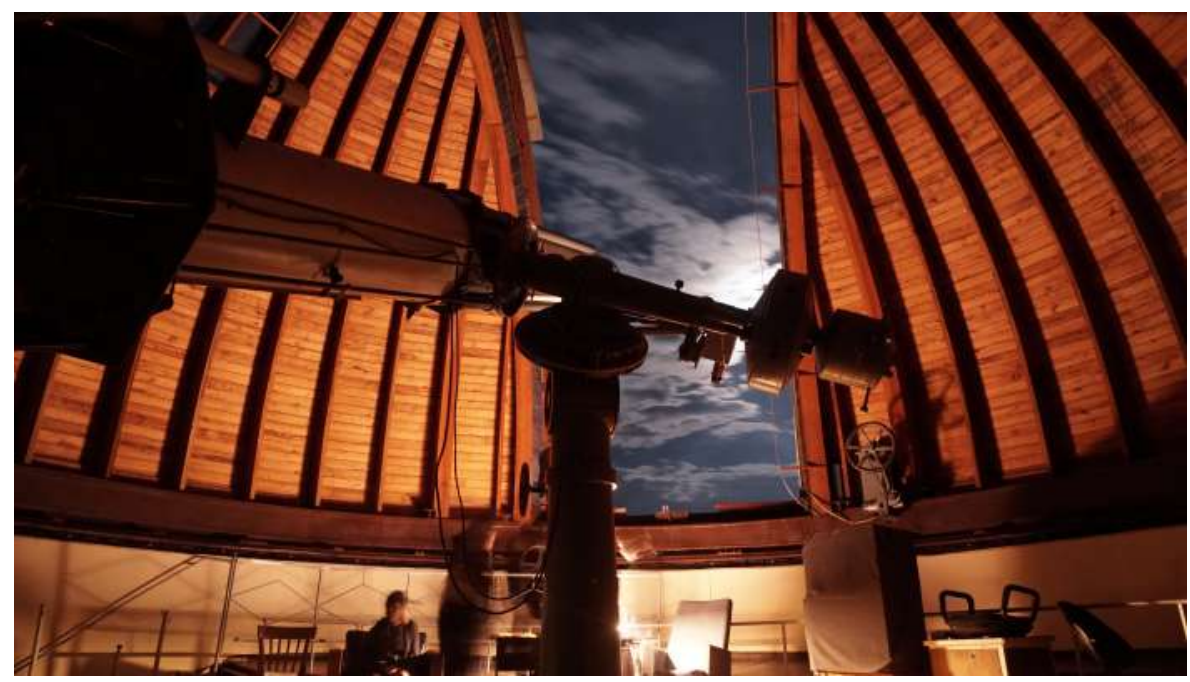

Figure 1. Abastumani observatory in Georgia

for astro-photographers, as they can spend the night without disturbing professional astronomers on the observatory's field. Furthermore, the observatory's managers' efforts to register the First Byurakan Survey as UNESCO's Memory of the World have attracted tourists interested in contemporary history and documentation. The official FBS page at UNESCO states: "First Byurakan Survey (FBS or Markarian survey) contains the records of a unique astronomical survey carried out by the Byurakan Astrophysical Observatory (BAO) from 1965-1980. The survey involved the largest-ever astronomical study of the nearby universe and is considered one of the most important achievements of 20th-century astrophysics."

\subsection{Shamakhi Observatory of Azerbaijan}

Named after Nasreddin Tusi, the Shamakhi Observatory of Azerbaijan was established in 1959, 145 $\mathrm{km}$ east of Baku, and $22 \mathrm{~km}$ north of Shamakhi. The observatory is located at an altitude of 1,435 to 1,500 meters above sea level and hosts a 2-meter telescope. In total, there are four telescopes to work on the night sky and two solar telescopes in this observatory. The observatory was rebuilt between 2009 and 2013. Housing facilities at the observatory are no doubt better than other counterparts in the Caucasus. However, construction near the observatory's grounds could pose a threat to the region's dark skies.

\subsection{The BTA-6 Observatory}

The BTA-6 Observatory is home to the largest Eurasia telescope. The telescope is located near Mt. Pastukhova and at an altitude of 2070 above sea level. The first exposure of the telescope, located north of the Caucasus Mountains, took place in 1975. The telescope was the world's largest telescope before the Keck-1 telescope was built in the 1990s. Although this location has a low level of light pollution, it has not been targeted by astrotourists due to the distance from major cities. This observatory is $380 \mathrm{~km}$ away from Krasnodar and nearly $500 \mathrm{~km}$ from Sochi, making it difficult to visit. However, its history and rich nature can make this observatory a popular destination for astrotourists.

\section{Impacts of Astrotourism}

Strengthening astrotourism maintains sustainable development in many target areas. Protecting dark skies against light pollution besides protecting the world's natural and cultural heritages are just some of the advantages of astrotourism. At best, astrotourism can change the course, improve, and even rebuild and strengthen the livelihoods of the people of a region. So changing the style of mass tourism to alternative tourism in the region, fund-raising for developing and better maintenance of 


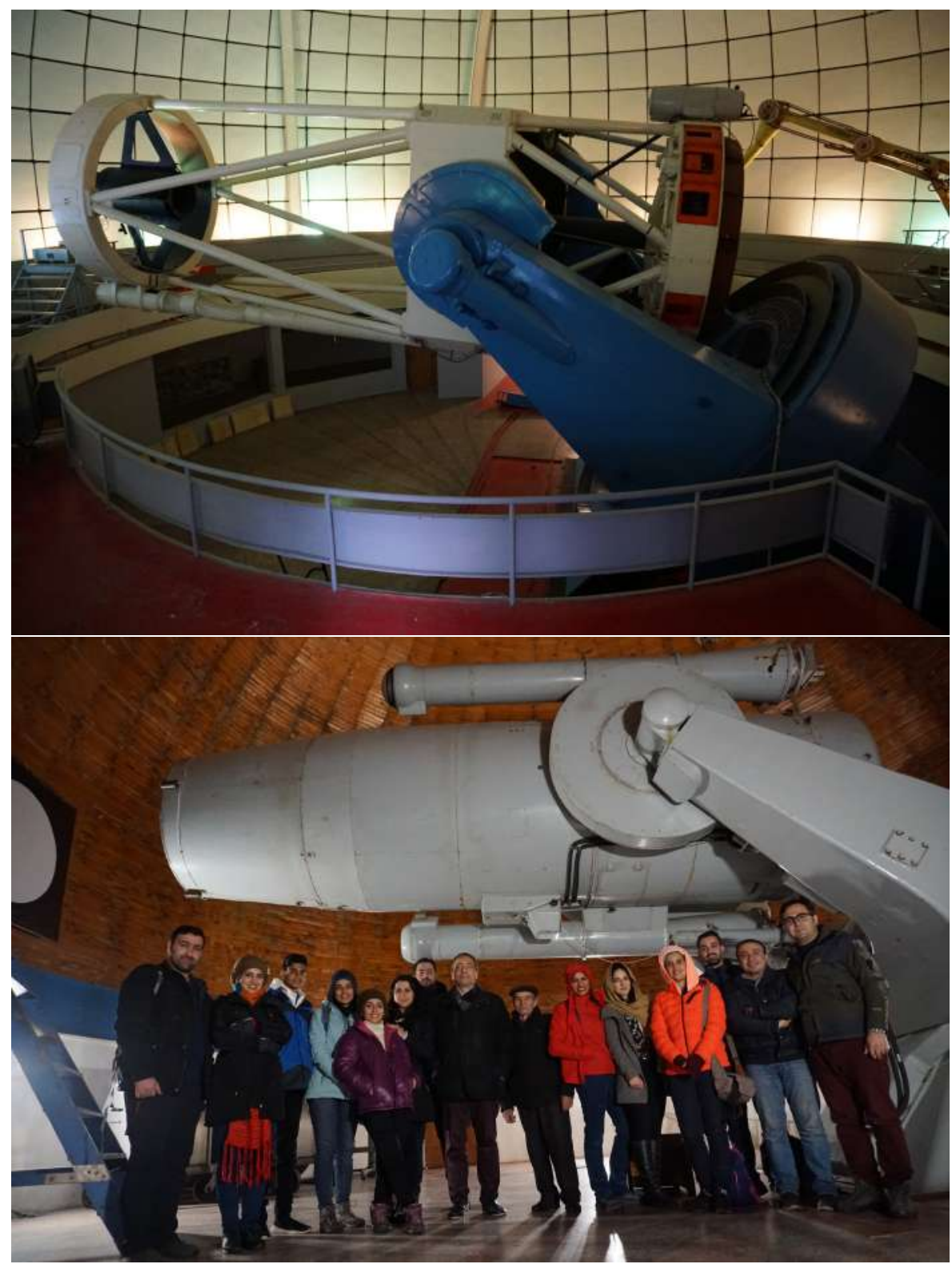

Figure 2. Byurakan observatory in Armenia

observatories along with protecting of observatories against changing policies, and providing sustainable livelihood for local people are other advantages of astrotourism. Last but not least, encouraging people to rediscover their place in the universe is one of the best achievements of astrotourism that will lead to more peace.

\section{Opportunities}

There are several hidden treasures of astronomy in Caucasus. The hidden treasures in the Caucasus region are pure nature, the night sky free from light pollution, and observational tools with a rich history. Traditionally, these destinations were available to the people of this region. However, with the brilliance of tourism in these countries, especially in the last decade, and also with the advent of astrotourism, new opportunities have been presented to these astronomical centers. Note that the other observatories in the area are either not so professional or close to the public. Easy access for Iranian, Russian, and Turkish people by the air and land makes them an attractive destination for astronomy enthusiasts in the Eurasian region. Locating between and around the Caucasus with special climate and history, from Soviet Union to the post-Soviet era, behind these astronomical centers will absorb more non-science related tourists to these points. 

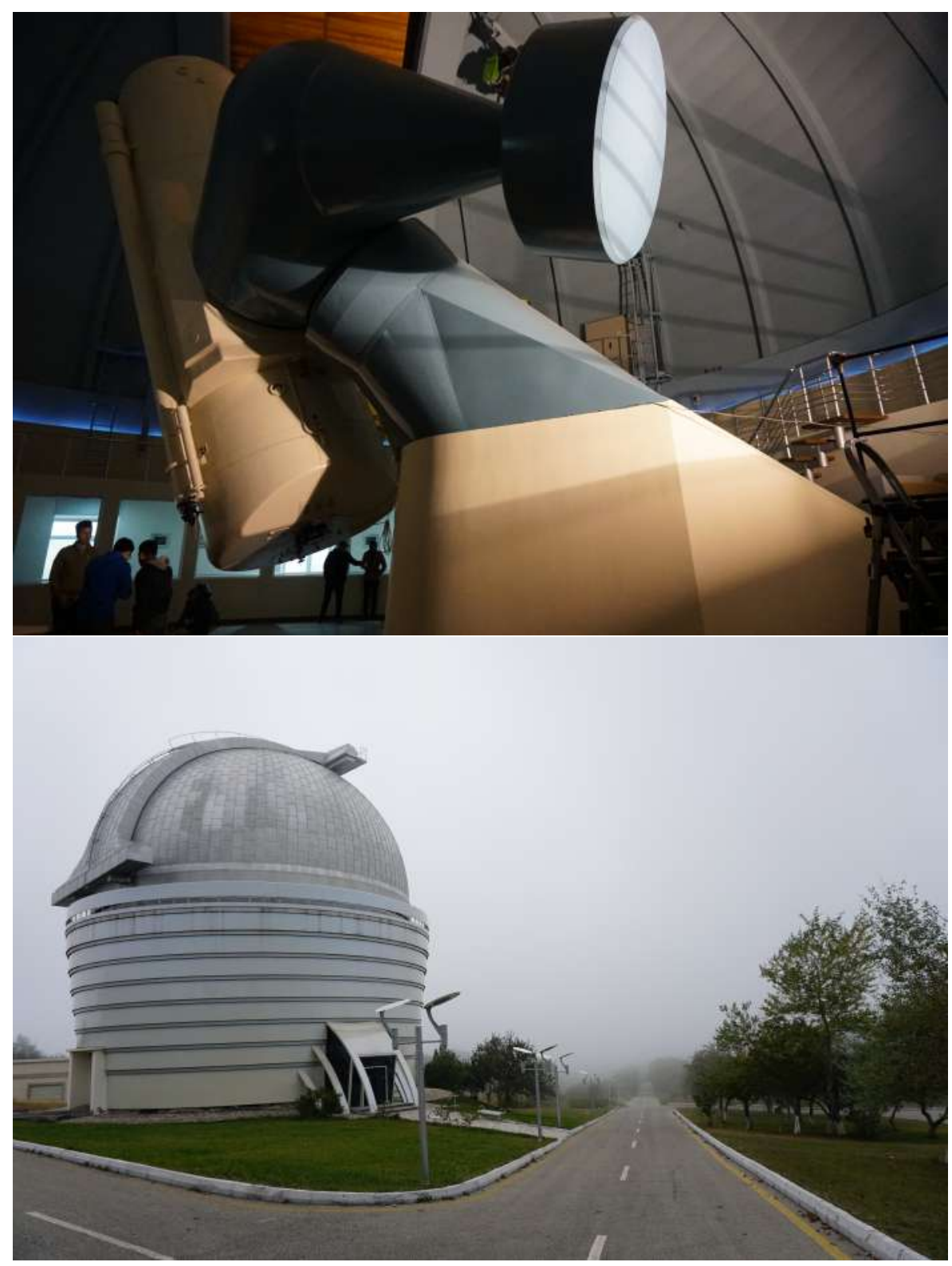

Figure 3. Shamakhi observatory in Azerbaijan

\section{The gateway to the future}

With all the advantages that observatories have in the Caucasus region, there are still disadvantages and problems that make it difficult for tourists to connect with these observatories. There are a few updated information about observatories on websites of the observatories, especially in English. Information on travel guide websites is not reliable enough. Scientists or public relations are planning these programs with limited assistance from travel agencies. There is no online booking system that works, and there are no advanced tour packages, such as mountain climbing and stargazing. However, there are many ways to improve the hospitality of astrotourists in these centers, which I would like to mention here: Planning new routes for astrotourism in collaborations of countries, such as from Karahunj to Abastumani. Associating nightscapes with heritage is a logical step in astrotourism Metodijeski et al. (2017). Another solution is creating an online platform for reservation and contracting with agents in other countries. Astrotourism needs to be better publicized in order to grow. It is a niche with such potential that it could be a good idea for travel agencies to better publicize the destinations that promote such tourism Matos (2017). In the end, there are two other suggestions: Planning two types of programs, one for the public and one for amateur astronomers and making new and special festivals such as Messier marathons in collaboration with amateur astronomers 
(especially Iranian amateur astronomers). Undoubtedly, there is much potential for improving the level of astrotourism in this region.

\section{Conclusions}

The undeniable potential of the Caucasus region, from pristine nature to rich history, and the fact that the observatories of this region are open to the public, provide a unique opportunity to improve astrotourism in these centers. By taking advantage of this opportunity, these observatories, in addition to having a favorable cultural impact on society and preserving the night sky, have a direct impact on improving the livelihoods of the people of their region. These observatories can also become successful examples for other observatories in other countries to protect their astronomical history.

\section{References}

Belij M., Tadic M., 2015, Glasnik Srpskog geografskog drustva, 95(3), 59

Fayos-Solà E., Marín C., Rashidi M., 2016, in Encyclopedia of Tourism. Springer, pp 56-57

Jiwaji N. T., 2016, Huria: Journal of the Open University of Tanzania, 23(1), 106

Labuda M., Pavličková K., Števová J., 2016, E-review of Tourism Research, 13, 1

MacMillan G., 2016, Preserving our Night-time Skies . Doctoral dissertation, Galway-Mayo Institute of Technology

Matos A. L., 2017, Terrestrial Astrotourism-Motivation and Satisfaction of Travelling to Watch the Night Sky . Doctoral dissertation, Aalborg University

Metodijeski D., Taskov N., Filiposki O., Mitreva E., 2016-2017, in Giving gift to God: evidences of votive offerings in the sanctuaries, temples and churches: proceedings of the 1 st \& 2nd International archaeological conference "Kokino", held in Skopje \& Kumanovo. National Institution Museum of Kumanovo, pp 237-244

Mickaelian A., Farmanyan S., 2016, Mediterranean Archaeology and Archaeometry, 16(4)

Mitura T., Bury R., Begeni P., Kudzej I., 2017, European Journal of Service Management, 23, 45

Tadic M., 2016, Glasnik Srpskog geografskog drustva, 96(1), 127 